\title{
Estrategias de adaptación de los saberes científicos en «Principios de botánica en cartas a una Señora»
}

Strategies of adaptation of scientific knowledge in «Principios de botánica en cartas a una Señora»

BARBARA ŁUCZAK

Uniwersytet im. Adama Mickiewicza w Poznaniu 


\title{
RESUMEN
}

«Principios de botánica en cartas a una Señora» es un curso elemental de botánica que apareció en el Semanario de Agricultura y Artes dirigido a los Párrocos en el año 1802. Dirigido formalmente a un destinatario femenino, fue basado en la primera parte del tratado Descripción de las plantas de Antonio José Cavanilles (1802). En el artículo nos planteamos examinar las modificaciones que el redactor introdujo al contenido del curso a la hora de adaptarlo al lector no especializado. También comentamos la relación que existe entre los «Principios de botánica en cartas a una Señora » y las «Cartas elementales sobre botánica» de Jean-Jacques Rousseau.

Palabras clave

Semanario de Agricultura y Artes dirigido a los Párrocos, formación de las mujeres; manuales de botánica, divulgación científica.

\begin{abstract}
«Principios de botánica en cartas a una Señora» is an elementary course of botany published in Semanario de Agricultura y Artes dirigido a los Párrocos in 1802. Formally addressed to a lady, it was based on the first part of the treatise Descripción de las plantas written by Antonio José Cavanilles (1802). In the article we examine the modifications introduced by the author in order to adapt the course to the non-specialized reader, we also comment on the existing relationship between «Principios de botánica en cartas a una Señora» and «Lettres élémentaires sur la botanique» by Jean-Jacques Rousseau.
\end{abstract}

KeY WordS

Semanario de Agricultura y Artes dirigido a los Párrocos, women's education; manuals of botany, scientific popularization.

Recibido: 16 de enero de 2020. Aceptado: 19 de marzo de 2020. 
En el año 1802, desde el 30 de septiembre hasta el 28 de octubre, durante cinco jueves consecutivos, se pudieron leer, en el Semanario de Agricultura y Artes dirigido a los Párrocos, las entregas sucesivas de «Principios de botánica en cartas a una Señora» ${ }^{1}$. Este curso elemental de botánica consta de veinticinco cartas aparecidas en los números 300 a 304 de la revista ${ }^{2}$, cada una de las cuales lleva el número y el título que presenta su temática. Dirigido formalmente, como lo anuncia su título mismo, a un destinatario femenino, está basado en «Principios elementales de botánica», la primera parte del tratado Descripción de las plantas que D. Antonio José Cavanilles demostró en las lecciones públicas del año 1801, precedida de los principios elementales de la botánica (1802). En el presente artículo nos planteamos averiguar qué tipo de modificaciones, tanto formales y estructurales como de contenido, introdujo el redactor $^{3}$ del curso publicado en el Semanario a la hora de adaptar el texto de Cavanilles; paralelamente, comentamos las especificidades de la relación que los «Principios» mantienen con las «Cartas elementales sobre botánica» de Jean-Jacques Rousseau.

En la parte inicial de la primera carta se esboza el marco de enunciación en el que el redactor sitúa su presentación de los contenidos botánicos:

1 El presente trabajo se ha realizado en el marco del proyecto «Formas de vida, formas de literatura» (0237/NPRH4/H2b/83/2016, Programa Nacional del Desarrollo de las Ciencias Humanas) financiado por el Ministerio de Ciencia y Educación Superior polaco.

2 Semanario de Agricultura y Artes dirigido a los Párrocos, 300 (1802), págs. 209-224; 301 (1802), págs. 226-239; 302 (1802), págs. 242-256; 303 (1802), págs. 261-272; 304 (1802), págs. 279-287. Teniendo en cuenta la numeración continua de la revista, en las citas extraídas de «Principios de botánica en cartas a una Señora» señalamos, entre paréntesis, en el texto base, la página en la que se encuentra el fragmento. Utilizamos la versión abreviada de los títulos: Semanario por Semanario de Agricultura y Artes dirigido a los Párrocos y «Principios» por «Principios de botánica en cartas a una Señora». Hemos modernizado la ortografía de los títulos y de las citas. Las cursivas en las citas son siempre del original.

3 Según el «Índice de los autores» que cierra el tomo XII del Semanario (1802), los «Principios» fueron redactados por el mismo Antonio Cavanilles. No obstante, considerando el tono elogioso con el que el autor del curso se refiere a la figura de Cavanilles y los rasgos de su estilo, Elena Serrano llega a suponer que el texto fue preparado por Juan Antonio Melón, uno de los redactores del Semanario; Elena SERrano, Science for Women in the Spanish Enlightment 1753-1808, tesis de doctorado (mecanoscrito), Barcelona, Universitat Autònoma de Barcelona, 2012, pág. 116, n. 110. Frente a esta controversia, en el artículo nos referimos al redactor anónimo del curso. 
No bien has acabado, amable C. de leer las cartas en que te he ido dando un compendio de la química cuando ya quieres empeñarme en que te escriba otras sobre la botánica con el fin de dedicar a ella a la tierna Matilde que tan inclinada ves a las flores. Mejor era que hubiese comenzado nuestra correspondencia por este y otros ramos de la historia natural antes de llegar al estudio analítico de la naturaleza, que es el nombre que se debiera dar a la que llaman química; pero ya hemos invertido el orden empezando por donde habíamos de acabar: sin embargo trataré de complacerte según pueda (209).

El redactor de los «Principios» afirma responder a la petición de C., deseosa de conocer los fundamentos de botánica para poder instruir a su hija. En la primera frase del fragmento citado se menciona también otro curso cuyas últimas entregas se presentaron en la misma revista pocas semanas antes de la publicación de los «Principios». Aparecido en el Semanario entre el 22 de octubre de 1801 y el 5 de agosto 1802, formado de cincuenta y cinco cartas distribuidas en tres grupos ${ }^{4}$, contenía los fundamentos de química. Algunos de sus aspectos formales resultan importantes para la problemática que estamos tratando, razón por la cual vamos a comentarlos brevemente. El curso se publicó en el Semanario bajo el título de «Compendio de la química acomodado a la instrucción de las mujeres», presentado como «extracto de una obrita italiana» ${ }^{5}$. Efectivamente, en su exposición, el redactor-traductor español seguía La chimica per le donne de Giuseppe Compagnoni (1796), un curso de química redactado en cartas dirigidas a una mujer. En la adaptación española, esta figura femenina lleva el nombre de C., el mismo que la destinataria de los «Principios» ${ }^{6}$. En la parte introductoria se precisa el objetivo del curso:

A pesar de cuanto se ha hecho para promover el estudio de la química, no ha salido todavía un libro que presente los elementos de esta nueva ciencia de una manera tan sencilla y clara que sea bastante para instruir a los curiosos sin aquel matalotaje de palabras y aparatos que fastidian a los que de propósito no se dedican a la facultad; y esta consideración es la que me ha obligado a escribirla en

4 «Compendio de la química acomodado a la instrucción de las mujeres», Semanario, 251 (1801), págs. 269-272; 252 (1801), págs. 274-288; 253 (1801), págs. 293-303; 254 (1801), págs. 307-320; 255 (1801), págs. 326-336; 256 (1801), págs. 343-349; 266 (1802), págs. 67-80; 267 (1802), págs. 84-94; 268 (1802), págs. 99-112; 269 (1802), págs. 115-128; 270 (1802), págs. 131-143; 271 (1802), págs. 147-159; 290 (1802), págs. 50-64; 291 (1802), págs. 68-80; 292 (1802), págs. 85-94.

«Compendio de la química», pág. 269.

6 Al principio de la primera de las cartas que forman el «Compendio de la química» leemos: «Me dices, amable C., que quieres aprender la química por ser ciencia de moda, y porque siguiendo la moda en el estudio, no se tendrá por el octavo de los vicios capitales»; «Compendio de la química», pág. 272. 
cartas a una Señora muy instruida, en las que se hallará todo el orden de los conocimientos químicos que han llegado hoy a tener tanta celebridad, para complacer a aquellos que desean tener idea clara de esta ciencia, de la cual nada se puede comprehender ni decir sin entender las palabras de que usa ${ }^{7}$.

La elección del destinatario —una «señora muy instruida», pero sin conocimientos de la materia que desea aprender - parece responder bien al objetivo del curso que es el de «instruir a los curiosos». También justifica el uso de la forma epistolar escogida para la presentación de los contenidos científicos.

Al preparar la adaptación del tratado de Cavanilles para ser publicada en el Semanario, el redactor la vincula con el «Compendio de la química» aplicando los mismos procedimientos formales. Esta decisión implica retomar la figura del personaje femenino en tanto que destinataria interna del curso y la presentación en forma epistolar. Si el redactor buscaba un modelo que reuniera estas características, se le pudo ocurrir la idea de seguir las «Cartas elementales sobre botánica» de Jean-Jacques Rousseau. En los años 70 del siglo XVIII el filósofo genovés había dirigido a Madame Delessert una serie de ocho cartas que contenían un curso elemental de botánica. Rousseau presenta a su chère cousine los fundamentos de la botánica, que ella, cuando lo considere oportuno, transmitirá a su hija, que en aquel momento tiene cuatro años. Las «cartas sobre botánica», que formaban parte de una correspondencia bastante más extensa que el pensador mantenía con la señora Delessert, pronto se publicaron en forma de curso ${ }^{8}$ y ganaron notoriedad. En 1785 fueron traducidas al inglés por Thomas Martyn, profesor de botánica en la Universidad de Cambridge, quien continuó el curso de Rousseau con veinticuatro cartas surgidas de su propia pluma en las que expuso el sistema de clasificación de las plantas elaborado por Linneo ${ }^{9}$.

En los «Principios» fácilmente reconocemos una situación narrativa semejante a la de las «Cartas elementales sobre botánica» de Rousseau. «Vuestra idea de entretener un poco la vivacidad de vuestra hija y de ejercer su

7 «Compendio de la química», pág. 269. 531-588.

Jean-Jacques Rousseau, Collection complète des œuvres, vol. 7 (Mélanges), II, Genève, 1782, págs.

9 Ann B. Shteir precisa que en Gran Bretaña: «The Rousseau-Martyn Letters on the Elements of Botany (1785) went through eight editions over the next thirty years as a very influential piece of popular botany writing»; Ann B. Shteir, Cultivating Women, Cultivating Science. Flora's Daughters and Botany in England 1760-1860, Baltimore \& London, The John Hopkins University Press, 1996, pág. 19. Utilizo la primera edición: Jean-Jacques Rousseau \& Thomas MarTyn, Letters on the Elements of Botany Addressed to a Lady. By the Celebrated J.J. Rousseau. Translated into English with Notes and Twenty-Four Additional Letters, Fully Explaining the System of Linnceus. By Thomas Martyn, B. D., Professor of Botany in the University of Cambridge, London, 1785. 
atención sobre objetos agradables y variados como las plantas me parece excelente $[. ..]{ }^{10}$, escribía el filósofo al comienzo de su primera misiva. La figura de «la tierna Matilde» aparecida en el fragmento inicial de los «Principios», citado arriba, hace pensar en la hija de la señora Delessert ${ }^{11}$. Ambos textos presentan entonces a una madre que se dirige a un experto para que le enseñe los fundamentos de botánica que ella, en el futuro, transmitirá a su hija (o sus hijos ${ }^{12}$ ). Pero si en sus cartas, particularmente en la primera, Rousseau hacía diferentes referencias a la figura de «nuestra querida pequeña botánica», «nuestra pequeña botanófila (amante de la botánica) ${ }^{13}$ », a sus capacidades perceptivas y físicas, o a la necesidad de adaptar los contenidos de aprendizaje a la edad de la niña, etc., en los «Principios» las referencias a la figura de Matilde quedan reducidas a unas escasas menciones, necesarias para hacer comprensible el marco de enunciación. De esta forma, la introducción de la figura de Matilde se convierte en un procedimiento formal, que inscribe los «Principios» en la tradición de los cursos de botánica dirigidos a un destinatario femenino y/o infantil ${ }^{14}$.

Como ya hemos señalado, los «Principios» son adaptación de una obra del célebre botánico Antonio Cavanilles. En 1801, Cavanilles fue nombrado director del Real Jardín Botánico de Madrid, donde, entre otras funciones, desempeñó una tarea docente consistente en una serie de clases abiertas al público, que luego serían recogidas en su Descripción de las plantas ${ }^{15}$. El libro consta de dos partes principales: la primera, titulada «Principios elementales de botánica», contiene una presentación sistemática de la anatomía de las

10 Jean-Jacques Rousseau, «Cartas elementales sobre botánica», Cartas sobre botánica, trad. Fernando Calderón Quindós, Oviedo, KRK Ediciones, 2017, págs. 99-201; pág.105.

11 En las ocho cartas que forman el curso de botánica de Rousseau no se menciona el nombre de Madelon, hija de la señora Delessert. Este aparece, en cambio, en la restante correspondencia intercambiada entre Rousseau y Delessert.

12 En las Cartas elementales de botánica se mencionan también otros hijos de la señora Delessert: «Si sólo damos a vuestros hijos una ocupación divertida, renunciamos a la mitad mejor de nuestro fin, que es, divirtiéndolos, ejercitar su inteligencia y acostumbrarlos a la atención»; Rousseau, Cartas sobre botánica, págs. 150-151.

13 Rousseau, «Cartas elementales sobre botánica», págs.115 y 165.

14 No hace falta explicar que detrás del modelo de las «Cartas elementales sobre botánica» de Rousseau se esconde toda una tradición de considerar la botánica como una disciplina particularmente adecuada para las mujeres y las niñas. En los «Principios», el estudio de la botánica es presentado como «sencillo, [...] acomodado a la capacidad de los niños, y [...] propio para entretener su curiosidad natural» «y aun de mayor atractivo para las niñas por su inclinación a las flores, de las que principalmente trata la botánica»; Semanario, págs. 210 y 211.

15 José María LóPEz-Piñero, «La obra botánica de Cavanilles», en VVAA, Antonio José Cavanilles (1745-1804). Segundo centenario de la muerte de un gran botánico, Valencia, Real Sociedad Económica de Amigos del País, 2004, págs. 11-146; pág.114. 
plantas y de la taxonomía linneana, modificada en algunos aspectos por el autor del tratado; en la segunda se comentan los «Géneros y especies de plantas demostradas en las lecciones públicas del año 1801». Los «Principios» siguen de manera bastante fiel la primera parte del tratado, siendo algunos de sus pasajes citas textuales del original. No obstante, en diferentes momentos encontramos también cambios respecto al texto de Cavanilles, los cuales vamos a comentar ahora.

Una primera modificación la observamos en la estructura del contenido. El redactor de los «Principios» presenta al comienzo del curso, en las cartas I-III, las partes de la planta relacionadas con el proceso de fecundación, esto es, la flor y el fruto, mientras que en el tratado de Cavanilles los apartados correspondientes a estas partes aparecen solo después del comentario de los «órganos vitales», a saber, la raíz, el tallo, los pedúnculos, las hojas, etc. Asimismo, en los «Principios» los aspectos relacionados con la fecundación pasan a un primer plano, precedidos por una breve evocación del sistema linneano de la clasificación de los vegetales, basado, justamente, en la anatomía de las partes responsables de la fecundación. De esta manera, el redactor de los «Principios» sitúa el sistema linneano en el centro del interés de los lectores, aunque, al mismo tiempo, no deja de señalar que en su curso presenta una versión del sistema modificada — «sabiamente» (256)— por Cavanilles.

Otro cambio consiste en la sistemática eliminación de los nombres latinos que en el tratado de Cavanilles aparecen tanto en los términos relativos a la anatomía de las plantas como en las denominaciones de las especies. Esta tendencia se ve en particular en numerosas tipologías que se presentan en el curso (véanse, a modo de ejemplo, las clasificaciones de las hojas o de las bayas ${ }^{16}$ ). En algunas ocasiones los términos latinos se ven reemplazados por los españoles; así, donde Cavanilles escribe: «Las flores que los [estambres] tienen unidos en un solo cuerpo, y no tienen corolas amariposadas, se llaman Monadelfas [...] y los estambres Stamina monadelpha» ${ }^{17}$, en los «Principios», en la última parte de la oración, leemos: «y los mismos estambres se llaman también monadelfos» (219). Los ejemplos podrían multiplicarse.

Otro procedimiento que sirve para simplificar el aparato nocional es la sustitución de términos de origen latino por fórmulas descriptivas, que tienden a facilitar su comprensión. Así, por ejemplo, las «flores polipétalas» ${ }^{18}$ aparecidas

16 Antonio José Cavanilles, Descripción de las plantas que demostró en las lecciones públicas del año 1801, precedida de los principios elementales de la botánica, Madrid, La Imprenta Real, 1802, pág. XXVIIIXLI y XCIV. En los «Principios» dichas tipologías se encuentran en las págs. 248-251 (n. I-XIII) y 232.

17 Cavanilles, Descripción de las plantas, pág. LXXIV.

18 Cavanilles, Descripción de las plantas, pág. LXIII. 
en Cavanilles, en los «Principios» se reemplazan por «las flores que tienen más de [un pétalo]» (216). En otro momento, adaptando el fragmento: «En las Gramas $[\ldots]$ este receptáculo se llama Raspa (rachis), y es filiforme $[\ldots]{ }^{19}$, el redactor del curso escribe (al mismo tiempo eliminando el término en latín): «En las gramas se llama el receptáculo raspa, y es como un hilito (filiforme)» (218). Por otra parte, en los «Principios» desaparecen los pasajes dedicados a precisar la aportación de diferentes botánicos en el campo de la terminología (p. ej. la terminología relativa al receptáculo introducida por $\operatorname{Link}^{20}$ ).

El redactor también considera oportuno eliminar las referencias al debate científico que se desarrolla en el seno de la botánica. En los «Principios» se suprimen entonces, entre muchas otras, las referencias a la manera de entender el concepto de la corola por parte de diferentes botánicos, las opiniones sobre las causas del cambio de color de los pétalos o las observaciones sobre la importancia —o la irrelevancia- del color de la corola en la clasificación de las plantas ${ }^{21}$. El informe de una extensa discusión concerniente a la necesidad del órgano masculino para la generación, a lo largo de la cual Cavanilles evoca las opiniones y los experimentos de Linneo, Spallanzani, Senebier, Gaertner, Bulliard y otros ${ }^{22}$, en los «Principios» se resume con un lacónico: «por más que alguno otro haya pensado, que no siempre era necesario el fluido espermático para lograr semillas capaces de germinar y reproducir su especie» (221). Un ejemplo curioso de la tendencia a eliminar referencias al debate científico se encuentra en la parte dedicada a la fecundación, donde desaparece la polémica sobre los mecanismos de la formación de la semilla, en particular, la crítica de la teoría de la preexistencia de los embriones ${ }^{23}$. En su lugar, figura un elogio de la diversidad del mundo vegetal, representada en la imagen de las «bodas de las flores», "sus distintas costumbres, sus galas, sus hermosos colores y varios matices!» (227). Más adelante, se alaban la libertad, la independencia y la robustez que el estudio de las plantas garantiza al botánico. En otro momento, quedan eliminadas las observaciones concernientes a las ventajas y las desventajas del sistema taxonómico linneano ${ }^{24}$. Asimismo, los contenidos presentados en los «Principios» ganan en transparencia, «liberados» de divergencias y contradicciones propias del debate científico. El redactor del curso visiblemente desea no «inquietar» a

\footnotetext{
19 CaVanilles, Descripción de las plantas, pág. LXV.

20 Cavanilles, Descripción de las plantas, pág. LXIV.

21 Cavanilles, Descripción de las plantas, págs. LXVIII-LX.

22 Cavanilles, Descripción de las plantas, págs. LXVIII-LXXII.

23 Cavanilles, Descripción de las plantas, pág. LXXXIII.

24 Cavanilles, Descripción de las plantas, págs. CIV-CIX.
} 
los lectores del Semanario con las posibles inconsistencias y discrepancias en el seno de la disciplina.

Tanto es así que donde Cavanilles problematiza algún aspecto de la anatomía de las plantas, el redactor de los «Principios» opta por las ideas comúnmente aceptadas, invirtiendo en algún caso el sentido:

Hay ordinariamente [un estilo] para cada Ovario; y otras veces uno para muchos; o varios para uno. Aunque estas sean las expresiones recibidas, y con utilidad conocida en todos los sistemas; con todo parece verosímil que el número de estilos es aparente y exterior; y que se reducen siempre en lo interior del ovario a uno solo, del que hay comunicación a las cicatrices de los huevecitos por medio de los cordones umbilicales, para que se efectúe la fecundación ${ }^{25}$.

[Y] aunque es más verosímil, [sic] que el número de estilos sea aparente y exterior, y que en lo interior todos se reduzcan a uno solo que comunica con las cicatrices de los huevecitos por medio de cordones umbilicales para fecundarlos, sin embargo diremos que hay tantos estilos en una flor, cuantos se presenten separados desde su base exterior en el ovario (223-224).

Para simplificar el aparato nocional, el redactor no solo suprime o reduce referencias a las opiniones de los especialistas en materia botánica, sino que también, a menudo, decide evitar mencionar sus nombres. Si bien este procedimiento no tiene un carácter sistemático, en diferentes momentos los apellidos de Linneo, Jussieu, Lamarck, Gaetner, Daubenton, Desfontaine, Link, Rayo, Malpighio, Grew, Gettard y otros desaparecen o se ven reemplazados por fórmulas generales; por ejemplo:

A este espolón llamó Linneo Nectario, Nectarium, expresión vaga que adoptó también a otros órganos muy diversos como a glándulas, cerdas, escamas, apéndices, tubérculos, cuevas \&c. Así pues, como dice Jussieu, Lamarck, Ventenat y otros grandes Botánicos, se debe suprimir, porque solo sirve para confundir y obscurecer las descripciones y caracteres ${ }^{26}$.

A este espolón le han llamado hasta estos tiempos nectario; nombre que también se ha dado a otras partes de la flor, y que se debe suprimir para hacer más claras las descripciones (216).

25 Cavanilles, Descripción de las plantas, pág. LXXIX.

26 Cavanilles, Descripción de las plantas, pág. LXII. 
En el fragmento que acabamos de citar pueden observarse también otros tipos de modificaciones especificados anteriormente, a saber: la desaparición de términos en latín y la simplificación del discurso mediante la supresión de diferentes elementos que completan o ilustran los contenidos presentados. La tendencia al uso de fórmulas generales que sustituyen referencias a opiniones de los naturalistas que en Cavanilles se mencionan por apellido puede comprobarse también en otros momentos: «que algunos llaman útero» (213) aparece en vez de «llamado útero por Malpighio» ${ }^{27}$; «un célebre botánico» (284) en lugar del apellido de Bulliard ${ }^{28}$, etc.

Los pasajes relativos al debate científico no son los únicos eliminados por el redactor de los «Principios». De su adaptación desaparecen igualmente algunas descripciones de la estructura interna de las plantas (p. ej., el fragmento «su [del filamento] fábrica interior es de vasos sutiles y tejido celular» ${ }^{29}$ ), aunque hay que señalar que en otros casos este tipo de contenido se conserva (p. ej., la característica de la estructura interna del polen: «cada granillo del polen tiene una cutícula exterior, un tejido celular interno, y dentro una materia semejante a la cera» [220]). La razón de estas modificaciones puede explicarse por la manera de entender la botánica en el siglo XVIII; dedicarse al estudio de las plantas supone, sobre todo, contemplar su forma exterior:

Il est bon d'observer ici, que l'objet de la Botanique étant de fournir les moyens de reconnaître et de distinguer les plantes, les recherches des Botanistes ne doivent essentiellement porter que sur leurs parties extérieures. L'examen des organes internes appartient au Physicien qui cherche a découvrir les lois de la végétation, pour étendre la sphère de nos connaissances, et pour en tirer des conséquences utiles a l'humanités ${ }^{30}$.

La forma epistolar empleada en los «Principios» permite poner en práctica una serie de procedimientos que tienden a acercar el discurso al destinatario del curso. A estos fines sirve el cambio de la persona gramatical. La segunda persona del singular queda privilegiada respecto a la forma neutra utilizada por Cavanilles:

27 Cavanilles, Descripción de las plantas, pág. LXXXVIII.

28 Cavanilles, Descripción de las plantas, pág. CXXVIII.

29 Cavanilles, Descripción de las plantas, pág. LXVII.

30 Démonstrations élémentaires de botanique, à l'usage de l'École Royale Vétérinaire, vol. 1, Lyon, Jean-Marie Bruyset, 1766, pág. 24. La eliminación de los contenidos relativos a la estructura interna y la fisiología de los vegetales es una práctica que se observa también en otros textos de divulgación sobre botánica dirigidos a las mujeres; sobre este aspecto véase Barbara ŁuczaK, «La botanique (adaptée) pour les femmes dans la Bibliothèque universelle des dames», Studia Romanica Posnaniensia, 44/4, 2017, págs 5-23; pág. 22. 
Obsérvase este tejido, si se corta transversalmente el tronco, y entonces se pueden contar los años del árbol por el número de círculos ${ }^{31}$.

[...] como observarás en un tronco cortado transversalmente, y entonces puedes contar los años que tiene el árbol por el número de círculos o capas concéntricas de la madera (244).

Pomo (Pomum), es un pericarpio más o menos carnoso, sin ventallas, con celdas membranosas o huesosas situadas cerca del eje del fruto.

Esta definición abraza multitud de frutos que Linneo llamó bayas como los del Serval, Níspero y otros, en cuyo interior no se descubre la especie de caja que vemos en las Peras y Manzanas ${ }^{32}$.

Pomo es un pericarpio más o menos carnoso sin ventallas, con celdas membranosas o huesosas situadas cerca del eje del fruto, como ves en el níspero, en cuyo interior no descubres la caja que cubre a las semilla en las peras y manzanas (232);

o también respecto a la primera persona del plural, propia del discurso científico:

Pero si cortamos dicho tronco transversalmente, ni veremos capas concéntricas, ni canal medular, ni producciones medulares como en los cortes transversales de las Dicotiledones ${ }^{33}$.

[C]ortado este trasversalmente, no verás en él capas concéntricas ni canal medular, como en los cortes trasversales de las plantas dicotiledones (245).

A este mismo grupo de procedimientos pertenece el cambio de registro que se observa cuando el redactor de los «Principios» opta por recurrir a expresiones propias del lenguaje coloquial:

$\left[\right.$ El estambre] consta ordinariamente de tres partes $[\ldots]^{34}$.

[El estambre] regularmente consta de tres cosas [...] (219);

\footnotetext{
31 Cavanilles, Descripción de las plantas, pág. XIV.

32 Cavanilles, Descripción de las plantas, pág. XCIII.

33 Cavanilles, Descripción de las plantas, pág. XV.

34 Cavanilles, Descripción de las plantas, pág. LXVII.
} 
La mayor parte de los órganos que acabamos de ver en las plantas Dicotiledones, se encuentran también en las Monocotiledones $[\ldots]^{35}$.

En las plantas monocotiledones se observa también casi todo esto [...] (244).

Por otra parte y, hasta cierto punto, en contradicción con la tendencia que acabamos de señalar, en la adaptación del curso de Cavanilles encontramos pasajes de carácter bastante más «técnico» que en el original, debido a la eliminación de partes explicativas. Este rasgo se observa en particular en las tipologías de las partes anatómicas de los vegetales ${ }^{36}$ que el redactor de los «Principios» coloca casi sistemáticamente en notas a pie de página, con el objetivo de amenizar la lectura: «Ya veo que te repugnará toda esta cáfila de nombres que te pongo abajo para que te sean mis cartas menos enfadosas» (215), explica. Al mismo tiempo, frecuentemente omite las características de las categorías que está presentando, limitándose a mencionar los términos que les corresponden. Asimismo, en algunos pasajes, dichas tipologías se convierten en meras listas de términos cuyo significado, en el caso más extremo, ni es conocido ni tampoco se explica, sobre todo porque el que escribe a la amable C. no ilustra sus observaciones con las descripciones de las plantas, contrariamente a Cavanilles, quien ocasionalmente remite a las características de las especies presentadas en la segunda parte de su tratado ${ }^{37}$. A veces, los contenidos aparecen condensados de tal manera que el texto se hace difícilmente comprensible, redactado en párrafos extensos, que engloban diferentes aspectos tratados de una manera bastante más detallada por Cavanilles. Este tipo de exposición puede cansar por su monotonía y aridez, particularmente en un texto de divulgación. El redactor es consciente de este peligro, como se ve por los pasajes metadiscursivos que incluye en su texto (que, por otra parte, constituyen un lugar común en los cursos de botánica dirigidos a las mujeres):

Tienes razón en decir que son muy secas mis cartas cuando solo contienen listas de nombres $[\ldots](245)$.

35 Cavanilles, Descripción de las plantas, pág. XIV.

36 Así, por ejemplo, el redactor de «Principios» omite la introducción al apartado dedicado a las «hojas espúreas [sic]» (en CavanilLes, Descripción de las plantas, pág. XLI) y pasa directamente a presentar la clasificación de los órganos que se inscriben en esta categoría (252).

37 P. ej.: «Permanente, caedizo, pajoso, aristado, marginado, peloso, plumoso \&c., nombres conocidos y explicados con varios ejemplos en la página 188 y siguientes»; CavaniLles, Descripción de las plantas, pág. CII. 
Gracias a Dios que se han acabado las listas de nombres que tanto te enfadan [...] (254).

Aquí concluyen todas las reglas y preceptos que te bastan para comenzar la práctica de esta ciencia en que verás cuán frecuentemente tenemos que usar de los terminotes que tanto te han molestado [...] (267).

No obstante, insiste en la necesidad de aprender la terminología:

No creas que pierdes el tiempo en saber estos términos: hazte cuenta que son el abecedario del arte de conocer las plantas; y si no aprendes las letras o caracteres, te será imposible leer en él: ten un poco de paciencia hasta pasar de los principios, que siempre son áridos, y luego hallarás el premio de tu constancia (217).

Te ruego, estimada C., que no pierdas la esperanza de divertirte en la anatomía y descripción de las plantas, por más que ahora te canse esta al parecer minuciosa nomenclatura: en los elementos de la botánica, como en los de todas las demás ciencias, se necesita bastante paciencia para gozar después del fruto de ella (222).

Y como si fuera para consolar, añade: «Cada palabra de estas puedes ver lo que significa al examinar las flores que te se presentan en el campo, y en que verás estas diferencias» (224).

Finalmente, algunos pasajes aluden directamente al sexo de la destinataria interna del curso, recordando que se trata de un texto dirigido formalmente a una figura femenina. "La corola es lo más hermoso de la flor, y que tan frecuentemente os sirve de adorno a las mujeres» (215), leemos en algún momento; en otro se mencionan las dificultades que padecen las mujeres en España para asistir a los cursos de ciencias:

Si tú asistieses a las lecciones del sabio botánico [Cavanilles] cuyos elementos quieres que te vaya dando en mis cartas, comenzarías a conocer plantas desde el primer día, y sin trabajo te familiarizarías con esta nomenclatura indispensable, que oirías repetir frecuentemente a este maestro. En él hallarías la mayor claridad, aplicación y celo por los progresos de la enseñanza que está a su cargo y en que es infatigable; y verías cómo al entrar en el aula se entrega a cada discípulo un manojo de diversas plantas en flor, para hacer en la lección anatomía de ellas, y determinar con el Linneo en la mano la clase, género y especie de cada una cuando se les pregunta. 
En otros países concurren a estas aulas y a las de física y química muchas personas de tu sexo: entre nosotros estáis como desterradas de estas concurrencias, y aun en el teatro os tienen con separación, como si fuera sinagoga de judíos, no sin algunos inconvenientes (248).

En estas circunstancias desfavorables, las mujeres deben recurrir a formas indirectas de transmisión de saberes, que, en este caso, es un curso de botánica basado en el tratado de Cavanilles ${ }^{38}$. C. reaparece, una vez más, como representante del colectivo femenino cuando el redactor la anima a hacer «causa común con todas las de [s]u sexo» (261) contra una educación basada en la adquisición de unos principios de gramática y latín sin que los acompañen ciencias prácticas y útiles como la geografía, la historia natural, el dibujo o la economía rural. Por otro lado, en los «Principios» encontramos un elemento típico de los manuales de botánica dirigidos a las mujeres, que es el elogio hecho por el maestro contento de los progresos realizados por la discípula:

Celebro mucho tu constancia y la prolijidad con que has ido juntando cuantas especies de hojas has podido con el fin de formar una idea exacta de la significación de los nombres que se les dan en la inmensa lista que acompañó a mi Carta XVI (256).

Fórmulas parecidas aparecen tanto en las «Cartas elementales sobre botánica» de Rousseau:

Vuestra solución a la pregunta que os había hecho sobre los estambres de las crucíferas es perfectamente justa, y me demuestra que me habéis entendido bien, o mejor, que me habéis escuchado, pues sólo tenéis necesidad de escuchar para entender.

No puedo evitar comunicaros una duda que me ha venido al releer vuestra última carta. ¿Es posible que hayáis visto por vos misma los flósculos de la margarita grande? Confieso que esto me sorprende. A pesar de vuestra atención y vuestra penetración, debéis de haber tomado naturalmente los puntos amarillos del disco por otros tantos estambres, y los semiflósculos blancos del contorno por otros tantos pétalos. Os ruego me digáis, con la franqueza que conozco de vos, si nadie os ha

$38 \quad$ En las cartas que forman el curso se menciona también el tratado de Cavanilles que constituye la base de los «Principios». El redactor anima a C. a consultarlo para ampliar sus conocimientos botánicos: «y tú cuando quieras tener la curiosidad de entretenerte en saber algo de esta familia menuda [las algas], puedes consultar las lecciones dadas en nuestro jardín botánico en el año de 1801, y publicadas en 1802» (284). Sin embargo, en ningún momento se explica, por qué C. no acude directamente al libro de Cavanilles. 
ayudado. Si habéis encontrado esto por vos misma y vuestra pequeña compañía con sus finos ojos ha visto hasta ahí, me atrevo a pronosticar que en pocos años seréis la una y la otra únicas en vuestro sexo con madame la duquesa de Portland, en el pequeñísimo número de los verdaderos botánicos $[\ldots]^{39}$;

como en las que constituyen su continuación inglesa:

I have received, dear Cousin, very safe, all your packets, and cannot but admire the neatness with which you have arranged your plants, the care you have taken in having all the parts necessary to determine both the genus and species in your specimens, and the brilliancy of colour in most of the flowers. All this serves to show how much better the female fingers are adapted to such operations than ours. I am pleased also to hear that our little Botanist had so large a share in laying out and drying these plants, which I shall carefully preserve as a memorial of the industry and the adroitness of both. But what gives me the most pleasure is, to see that you have remarked with so much success in general, to which of the natural classes your plants belong. So that I am well convinced you have profited by my lessons, and have paid a due attention to my letters ${ }^{40}$.

En relación con esto se plantea la pregunta concerniente a las razones que habrían motivado la decisión de publicar en el Semanario una adaptación del tratado de botánica en forma de cartas dirigidas a una mujer. Independientemente de si los «Principios» fueron a parar efectivamente en las manos de muchas mujeres aficionadas a la botánica ${ }^{41}$, el redactor tenía sus razones. En pri-

39 Rousseau, Cartas sobre botánica, págs. 138 y 179-180.

40 Rousseau \& Martyn, Letters on the Elements of Botany, pág. 89.

${ }^{41}$ El tema es interesante, si consideramos los canales de divulgación de la revista, mediante la red de las parroquias esparcidas por el estado: el Semanario se dirige a los párrocos para que «sirviéndoles al mismo tiempo de lectura agradable, excite frecuentemente su celo a fin de que comuniquen a sus feligreses los adelantamientos, las mejoras, industrias e invenciones que se publiquen», como leemos en el prospecto aparecido en el primer tomo del Semanario (1797); Elisabel Larriba \& Gérard Dufour, El Semanario de Agricultura y Artes dirigido a los Párrocos (1797-1808), Valladolid, Ámbito Ediciones, 1997, pág.76. № obstante, Serrano considera que los «Principios» fueron efectivamente dirigidos a una audiencia femenina: «It is interesting to note that for the purpose of teaching the principles considered useful for agriculture, that is botany, chemistry, and natural history, the editors included three treatises addressed to women (Compendio de chimica acomodado a la instruccion de las mujeres, Principios de botánica en cartas a una señora and Elementos de historia natural en cartas a una señora). Texts for female audiences — popular since the times of Fontenelle's bestseller Entretiens sur la pluralité des mondes — were thought to be easier to understand than other instructive texts, and thus also appropriate for craftsmen and laypeople. Yet, as Melón argued, they were also aimed specifically at women, who were to properly exercise their newly enhanced social role as mothers of the 'new generations'»; Elena Serrano, «Making oeconomic people: The Spanish Magazine of Agriculture and Arts for Parish Rectors (1797-1808)», History and Technology: An International Journal, 2014, págs. 
mer lugar, como decíamos, la forma epistolar y el discurso dirigido a la amable C. le permitieron empalmar con el curso de química publicado anteriormente en el Semanario. Al mismo tiempo, la figura de la destinataria interna, tal como la construyó el redactor del curso, cumplía los requisitos del modelo de mujerdiscípula, consagrado por textos tan célebres como Entretiens sur la pluralité des mondes (1686) de Bernard de Fontenelle o Il newtonianismo per le dame ovvero dialoghi sopra la luce e $i$ colori (1737) de Francesco Algarotti, o también, en el ámbito de la botánica, las «Cartas elementales sobre botánica» de Rousseau. Asimismo, las «cartas a una señora» fácilmente pudieron convertirse en un curso elemental y servir como una fórmula idónea para un escrito de divulgación. En efecto, leyendo las «Cartas elementales sobre botánica» (17711774) de Jean-Jacques Rousseau y los «Principios» (1802) nos percatamos del proceso que se opera mientras pasamos del uno al otro. Las cartas de JeanJacques, que formaban parte de la correspondencia entre dos personas reales, se convierten en un modelo de manual de botánica dirigido al lector femenino ${ }^{42}$. El redactor español retoma esta fórmula tratándola como modelo de un curso elemental. En definitiva, detrás de la figura de C., se esconde un lector no especializado, un curioso, un aficionado al estudio de los vegetales. Si bien esta manera más amplia de considerar al destinatario era implícita en las cartas de Rousseau, una vez publicadas en forma de curso, en los «Principios» la figura del curioso invade y acaba por absorber la figura femenina, reducida, en gran medida, a un puñado de rasgos formales.

1-28, pág. 8 http://dx.doi.org/10.1080/07341512.2014.988424. La investigadora también sugiere que las cartas recogidas en los «Principios» fueron dirigidas a una mujer concreta conocida por el redactor; SERRANO, Science for Women, pág. 115.

42 Como tal son recogidas en la continuación inglesa de la obra de Rousseau, aunque, ya en esta etapa, se comenta su utilidad para cualquier otro apasionado de las plantas que desee conocer las bases de la disciplina. Martyn dedica su libro «to the ladies of Great Britain: no less eminent for their elegant and useful accomplishments than admired for the beauty of their persons»; RousseaU \& MARTYN, Letters on the Elements of Botany, pág. iii. Sam George comenta entonces que «Martyn openly courted female readers, capitalising on Rousseau's address to a young mother, significantly escalating a demand for botany books written for a particular class of enlightened British women and promoting botany as an elegant pursuit for 'Ladies'»; Sam GEorge, Botany, sexuality and women's writing 1760-1830. From modest shoot to forward plant, Manchester \& New York, Manchester University Press, 2007, pág. 43. No obstante, en el prefacio al volumen, Martyn añade, refiriéndose a las cartas de Rousseau: «I then thought that they had considerable merit; and that if they were disembarrassed from the chaos of fifteen quarto volumes, and translated into English, they might be of use to such of my fair countrywomen and unlearned countrymen as wished to amuse themselves with Natural History»; Rousseau \& Martyn, Letters on the Elements of Botany, pág. v. 